University of Nebraska - Lincoln

DigitalCommons@University of Nebraska - Lincoln

Papers in Biomaterials

Chemical and Biomolecular Engineering

Research and Publications

January 2002

\title{
Immobilization of Pseudomonas cepacia Lipase by Sol-Gel entrapment and its application in the hydrolysis of Soybean oil
}

Hossein Noureddini

Department of Chemical Engineering, University of Nebraska-Lincoln, hnouredd@unlnotes.unl.edu

X Gao

Department of Chemical Engineering, University of Nebraska-Lincoln

S Joshi

Department of Chemical Engineering, University of Nebraska-Lincoln

P R. Wagner

Isco, Inc., Lincoln Nebraska- 68504

Follow this and additional works at: https://digitalcommons.unl.edu/chemeng_biomaterials

Part of the Biomaterials Commons

Noureddini, Hossein; Gao, X; Joshi, S; and Wagner, P R., "Immobilization of Pseudomonas cepacia Lipase by Sol-Gel entrapment and its application in the hydrolysis of Soybean oil" (2002). Papers in Biomaterials. 6.

https://digitalcommons.unl.edu/chemeng_biomaterials/6

This Article is brought to you for free and open access by the Chemical and Biomolecular Engineering Research and Publications at DigitalCommons@University of Nebraska - Lincoln. It has been accepted for inclusion in Papers in Biomaterials by an authorized administrator of DigitalCommons@University of Nebraska - Lincoln. 


\title{
A Continuous Process for the Glycerolysis of Soybean Oil
}

\author{
H. Noureddini, ${ }^{a, 1}$, D.W. Harkey ${ }^{b}$, and M.R. Gutsman ${ }^{c}$ \\ aDepartment of Chemical Engineering, University of Nebraska, Lincoln, Nebraska 68588-0126
}

\begin{abstract}
A continuous process for the glycerolysis of soybean oil with pure and crude glycerol, the co-product from the transesterification of soybean oil was investigated in a pilot plant. The process was equipped with a motionless and a high-shear mixer. The experimental studies explored the effects of variations in mixing intensity, temperature, reactant flow rates, and reactant stoichiometry on the formation of MG and DG. The developed process resulted in high conversion of TG to $M G$. The most favorable conditions were $230^{\circ} \mathrm{C}, 40 \mathrm{~mL}$ min total flow, $25 \mathrm{~min}$ of reaclion time, 2.5:1 molar ratio of glycerol/soybean oil, and 3600 $\mathrm{rpm}$ for the reactions involving crude glycerol where the concentrations of MG and DG in the product were about 56 and 36 $w \mathrm{t} \%$, respectively. Under similar conditions, giycerolysis of pure glycerol resulted in 58\% MG and $33 \%$ DG. In general, higher temperatures and mixing intensities favored the conversion of TG to $M G$ and DG. Reaction temperature had a greater influence on the extent of the reaction than mixing. The formation of MG approached equilibrium for nearly all cases under investigations.

Paper rio. J10701 in JAOCS 81, xxx-xxx (January 2004).
\end{abstract}

KEY WORDS: Biodiesel, continuous process, crude glycerol, glycerolysis, mixing, monoglycerides, pilot plant, soybean oil, transesterification.

The glycerolysis of fats and oils produces MG and DG, which are used as surfactants and emulsifiers in a wide range of foods, cosmetics, and pharmaceutical products. MG are also used as lubricants in the textile industry and function as internal lubricants in the production of PVC $(1,2)$. In the past, $\mathrm{MG}$ and DG were produced mainly in batch processes at high temperatures $\left(220-260^{\circ} \mathrm{C}\right)$ in the presence of an inorganic catalyst such as sodium, potassinm, or calcium hydroxide (3). The glycerolysis of fats and oil with glycerol has been intensively pateuted as widening industrial uses were found for MG in the 1940s and 1950s. Sonntag (3) provided a complete collection of these patents in his review.

Enzymatic synthesis of MG by various lipase catalysts has received much attention in recent years owing to the lower energy requirements and selectivity of the catalyst (4-6). Although enzymatic synthesis of MG offers perhaps the greatest potential for future production, the relatively slow rate of enzymatic reactions and the high cost of enzymes have made the enzymatic processes economically unfavorable. Thus, all current industrial processes are based on physiochemical methods. However, recent developmeuts in enzymatic glycerolysis in-

*To whom correspondence should be addressed.

E-mail: hnoureddini@unl.edu clude the selective production of MG and DG by the introduction of binary solvents into the glycerolysis reaction (7) and high-yield glycerolysis of soybean oil by immobilized Candida antarctica in flowing supercritical carbon dioxide (8).

Continuous processes for the glycerolysis of TG have been reported in several articles and patents. Krustonov and co-workers (9) developed a pilot plant for MG emulsifiers by a TG glycerolysis method and reported production of $30-40 \mathrm{wt} \% \mathrm{MG}$ content. The Birnhaum and Lederer patent described a continuous alkaline-catalyzed glycerolysis process usiug uear-stoichiometric quantities of glycerol and 5-10\% recycle of the product (10). Demmering and Effey obtained high yields of MG (60\%) from the transesterification of glycerol with $\mathrm{TG}$ in an alkaline catalyst at $300^{\circ} \mathrm{C} \mathrm{(11).} \mathrm{Patents} \mathrm{by} \mathrm{Allen} \mathrm{and} \mathrm{Campbell} \mathrm{(12)} \mathrm{and}$ Chang and Wiedermanu (13), describe other examples of coutinuous, alkaline-catalyzed glycerolysis processes.

The objective of this research was to develop a continuous process for the productiou of MG and DG. The glycerolysis reaction with pure and crude glycerol, a co-product from the transesterification of $\mathrm{TG}$, was studied. The reactiou temperature, mixing iuteusity, reactant flow rates, and the molar ratios of the reactants were the variables investigated iu this study. The experiments were conducted in a continuous pilot plant.

\section{EXPERIMENTAL PROCEDURES}

Materials. Refined and bleached soybean oil was provided by Archer Danieis Midland Company (Liucoln, NE). The FFA concentration of the oil was measured according to AOCS Method $\mathrm{Ca} 5 \mathrm{a}-40$ (14) and was determined to be $0.09 \%$. Sodium hydroxide (98.4\%) was obtained from Fisher Scientific Company (Fair Lawn, NJ). The standards for the glycerides were obtained frorn Sigma Chemical Company (St. Louis, MO). Methanol, HPLC-grade solvents, acetone, acetonitrile, and glycerol ( $99.8 \%$ ) were obtained from Mallinckrodt Baker, Inc. (Phillipsburg, NI).

The crude glycerol used in this study was prodnced in a pilot-scale continuous transesterification process. The major sectious of the pilot plaut included a pump station, preheating/premixing, mixing, residence tube, cooling, and settling. For details see Reference 15. The pilot plant was operated at about $90^{\circ} \mathrm{C}$, under a back pressure of about $25 \mathrm{psi}$. The molar ratio of methanol to soybean oil was $8: 1$, and the sodium hy droxide catalyst coucentration was $0.18 \mathrm{wt} \%$ (based on the soybean oil concentration). The product separated into two liquid phases after the transesterification reaction. The crude glycerol used in this study was the lower phase, whereas FAME were 


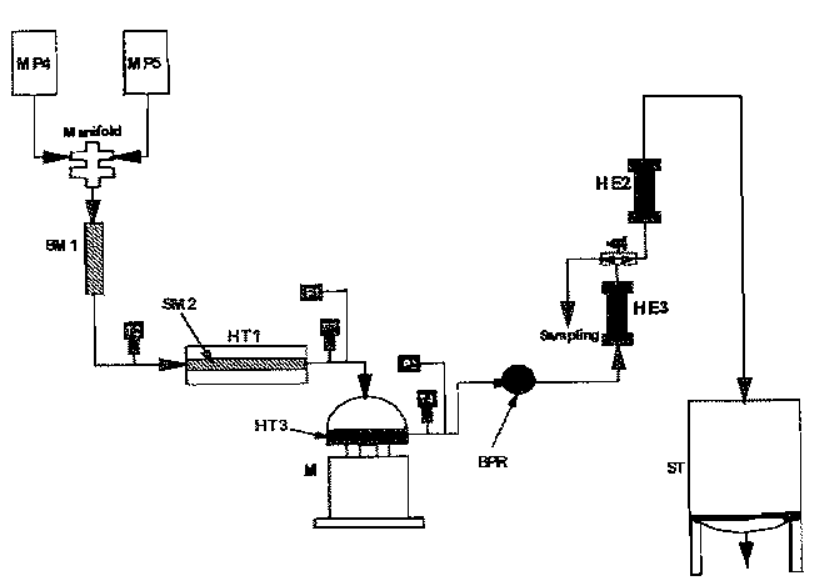

SCHEME 1

the main component of the upper phase. The crude glycerol contained most of the excess methanol used in the process, sodium hydroxide catalyst, FAME, and traces of $\mathrm{MG}, \mathrm{DG}$, and TG. The total concentration of glycerol, FAME and glycerides in the initial crude glycerol was about 45 wt $\%$ with the balance being methanol. The crude glycerol first was neutralized and then the excess methanol was removed from the glycerol phase iu a multistage batch distillation. The titration resnlts showed $0.33 \mathrm{wt} \%$ sodium hydroxide based on methanol-free glycerol. The neutralization of glycerol and removal of methauol also caused most of the FAME dissolved in the glycerol to separate out. The concentration of glycerol in the product was about 95 wt \%. No additional purification was carried out.

Equipment. A flow diagram for the pilot plant is shown in Scheme 1. (i) Pump station. Two inline E Series Pulsatron Pulsafeeder (Rochester, NY) metering pumps made up the pump station (MP4 and MP5). Both pumps converged to a manifold, which contained the tirst motionless premixer. One of the pumps was used for the soybean oil, and the other for the glycerol/sodium hydroxide mixture.

(ii) Preheating and premixing. A $120 \mathrm{~V}, 600 \mathrm{~W}$ Wailow (St. Louis, MO) silicone rubber heater was installed over the glycerol inlet tube to the pnmp (not shown in the flow diagram). This heating decreased the viscosity of the glycerol and made the pumping possible.

The reactants converged in the pump manifold and then were directed through two in-line motionless mixers (SMl and SM2). The first motionless mixer was made of polypropylene, and the second static mixer was made of 316 stainless steel. The latter was located inside a block heater (HT1). The flow tube ran down the middle of the heater. The motionless mixers were manufactured by Koflo Inc. (Cary, IL) and the heating elements used in the block heater were purchased from Watlow.

(iii) Heating/mixing. A continuous high-shear mixer (M) made by Stratco. Inc. (Kansas City, MO) was used to mix the reactants further. The high-shear mixer is based ou a rotor-stator design. The mixer had a capacity of $600 \mathrm{~cm}^{3}$ and was able to operate at temperatures up to $240^{\circ} \mathrm{C}$. The high-shear mixer was equipped with a Watlow band heater (HT3), which heated the mixer during startup, and as needed in the experiments. The band heater was $3.81 \mathrm{~cm}$ wide with a $30.48 \mathrm{~cm}$ diameter and was rated at $1000 \mathrm{~W}$. The high-shear mixer was connected to a variable-frequency drive manufactured by Utech Systems Associates lnc. (Milwaukee, WI).

(iv) Cooling system. The products were cooled using two miniature shell and tube heat exchangers made in our shop (HE2 and HE3). Tap water, which was constant at about $15^{\circ} \mathrm{C}$, was used as coolant. A valve was installed in between the two exchangers for sampling.

(v) System pressure. A Tescom 26-1700 self-contained spring-loaded back-pressure regulator (BPR) was located before the two miniature heat exchangers. The BPR was a precision release device that allowed fluid to escape at a rate to maintain the desired pressure. The system pressure was monitored with two Rosemount (model $1151 \mathrm{GP}$ ) gange pressure transducers (P1 and P2). Product was collected in a storage $\operatorname{tank}(\mathrm{ST})$

(vi) Control system. The control system was purchased from Landis and Gyr (Buffalo Grove, IL). 1t communicated with a personal computer through the control program Procomm Plus for Windows, developed specifically for the operation of the pilot plant, and used to achieve and maincain the set points and the operation parameters. This program coutrolled the operation of pumps, heaters, and mixers, and monitored various temperatures from thermocouples ( $\mathrm{T} 2,-3,-4)$ and pressures from the transducers.

Pilot plant operation. Sodinm hydroxide was initially dissolved iu glycerol by heating the mixture to about $50^{\circ} \mathrm{C}$. The concentration of sodium hydroxide was $0.18 \mathrm{wt} \%$, based on the total mass of the reactants. The flow rates of the soybean oil, and the glycerol/sodium hydroxide mixture were based on molar ratio of 2.5: 1 for glycerol and TG, respectively.

Initially, both heaters were set at $100 \%$ capacity until the desired temperature was reached. The heaters were then controlled to maintain the set temperature. The system was operated for a period of time that allowed steady-state conditions to be reached, or approximately the time for at least three system volumes to pass through the system. On a series of consecutive runs, this would allow the system to completely flush out the material from the previous run and come to a new steady-state condition. The duration of the pre-steady-state run time was determined by taking samples during this time for representative runs. Steady-state was assumed when further change in the composition of the product was observed. Each run was made twice. The reported values are the average of the two runs.

Analysis. An HPLC system with a pump (mode1 2350, ISCO, Lincoln, NE) and a refractive index detector (Refracto Monitor IV, Thermo Separation Products, Riviera Beach, FL) was used to analyze the products. A Spherisorb ODS 2 column $(250 \times 4.6$ $\mathrm{mm}, 8(-\mu \mathrm{m}$ pore size, $5-\mu \mathrm{m}$ particle size) was used for the separation. The temperature of the column was maintained at $35^{\circ} \mathrm{C}$ by a Brinkman RC 6 temperature bath. Data collection and analysis were performed with Hewlett-Packard (Wilmington, DE) Chemstation software. The mobile phase for the system was a 50:50 volumetric ratio of acetone and acetonitrile and was 
degassed before use in the system. The mobile phase flow rate was set to $0.7 \mathrm{~mL} / \mathrm{min}$. The components measured by HPLC included FAME, MG, DG, and TG. Standards for FAME, MG, DG, and TG were used to establish the calibration charts, which in turn were used to quantify samples that were analyzed.

\section{RESULTS AND DISCUSSION}

The study concentrated on the variations in temperature, reactants molar ratio, flow rate, and mixing intensity. Catalyst concentration was at $0.18 \mathrm{wt} \%$ based on soybean oil and was maintained at a constant level for all experiments.

Effect of flow rate. The pilot plant was operated at 35,40 , and $50 \mathrm{~mL} / \mathrm{min}$ of reactants flowing continnously through the system. This corresponded to total reaction times of 20,25 , and $28.5 \mathrm{~min}$, based on the total system volume of about $1000 \mathrm{~mL}$. For this set of experiments, the temperature was maintained at $220^{\circ} \mathrm{C}$, and mixing intensity was set to its maximum at 3600 rpm, or $100 \%$ power. Results showed a slight change in the formation of MG and the amount of unreacted TG and no significant change in the formation of DG over the flow rates tested (35-50 $\mathrm{mL} / \mathrm{min})$. MG concentration was highest, at about 62 $\mathrm{wt} \%$, at 35 and $40 \mathrm{~mL} / \mathrm{min}$ and decreased to about $58 \mathrm{wt} \%$ as the flow rate was increased to $50 \mathrm{~mL} / \mathrm{min}$. The percentage of unreacted TG was about $6 \mathrm{wt} \%$ at 35 and $40 \mathrm{~mL} / \mathrm{min}$ and 10 wt $\%$ at $50 \mathrm{~mL} / \mathrm{min}$. At flow rates of 35 and $40 \mathrm{~mL} / \mathrm{min}$, the equilibrium state of the esterification reactiou was approached, and the reaction was thermodynamically limited. The lower rate of formation of $\mathrm{MG}$ at $50 \mathrm{~mL} / \mathrm{miu}$ was expected and is due to a shorter residence times at this flow rate. At a flow rate of $50 \mathrm{~mL} / \mathrm{min}$, mixing is more intense and fewer mass transfer limitations are expected. The lower rate of formation of $\mathrm{MG}$ may also be attributed to the reaction rate limitations.

The results further suggest that the residence time of about $25 \mathrm{~min}$ is adequate for approaching equilibrium under the tested couditions. This residence time compares well with batch processing where $55 \mathrm{wt} \% \mathrm{MG}, 39 \mathrm{wt} \% \mathrm{DG}$, and $6 \mathrm{wt} \%$ TG were reported at a slightly higher temperature of $245^{\circ} \mathrm{C}$ and otherwise similar conditions (16). The residence time for the batch process was $20 \mathrm{~min}$; however, an additional $20 \mathrm{~min}$ was needed initially to heat the reactants to the reaclion temperature. The total cycle time for industrial batch glycerolysis processes may take up to $4 \mathrm{~h}(9)$.

Effect of molar ratio. The balanced stoichiometric molar ratio for an ideal reaction between glycerol $(G)$ and $T G$ is $2: 1$ for which $3 \mathrm{~mol}$ of $\mathrm{MG}$ are formed.

$$
\mathrm{TG}+2 \mathrm{G}=3 \mathrm{MG}
$$

However, the reaction is reversible and is believed to consist of three stepwise and consecutive reactions. MG are known to be the main reaction product, but DG are also formed and some unreacted TG also are found in the final equilibrium state. The reactiou steps are as follows:

$$
\mathrm{TG}+\mathrm{G} \Rightarrow \mathrm{MG}+\mathrm{DG}
$$

$$
\mathrm{DG}+\mathrm{G}=2 \mathrm{MG}
$$$$
\mathrm{TG}+\mathrm{MG}=2 \mathrm{DG}
$$

Owing to the reversibility of these stepwise reactions, the presence of glycerol in excess of the stoichiometric required amount is widely believed to enhance the formation of MG (3). However, the availability of glycerol for interaction with TG, which is measured as the concentration of glycerol in the TG phase, is the factor of primary interest. This concentration is a function of temperature and therefore, as long as a two-phase system (glycerol/TG) exists, the solubility of the glycerol in this phase will be independent of the total amount of glycerol that is present in the reaction medinm. This conclnsion, which is based on the solubility of the starting material, only holds at the onset of the reaction. As the reaction progresses, the concentration of MG increases, that of TG decreases, and the concentration of glycerol becomes much larger than its initial concentration in the TG phase. This suggests that, within certain limits, the excess amount of glycerol enhances the formation of the reaction products.

Experiments were conducted with molar ratios of glycerol/TG of $2: 1,2.5: 1$, and $3: 1$ at a mixing speed of $3600 \mathrm{rpm}$, temperature of $220^{\circ} \mathrm{C}$ and reactant volumetric flow rates of 50 $\mathrm{mL} / \mathrm{min}$. The results indicated no significant change in the formation of MG over the range investigated for the reactant ratios. MG levels of production were at about $62 \mathrm{wt} \%$ in all cases and were not affected by the ratio of glycerol/TG within the range of glycerol/TG that was tested. This was consistent with our previons suggestion about the effect of the initial solubility of glycerol in TG. It also implied that at molar ratios of glycerol/TG of $\geq 2$, the formation of $M G$ is independent of this ratio. This is in line with the conclusions from the previous section and further suggests both the approach toward the state of equi-

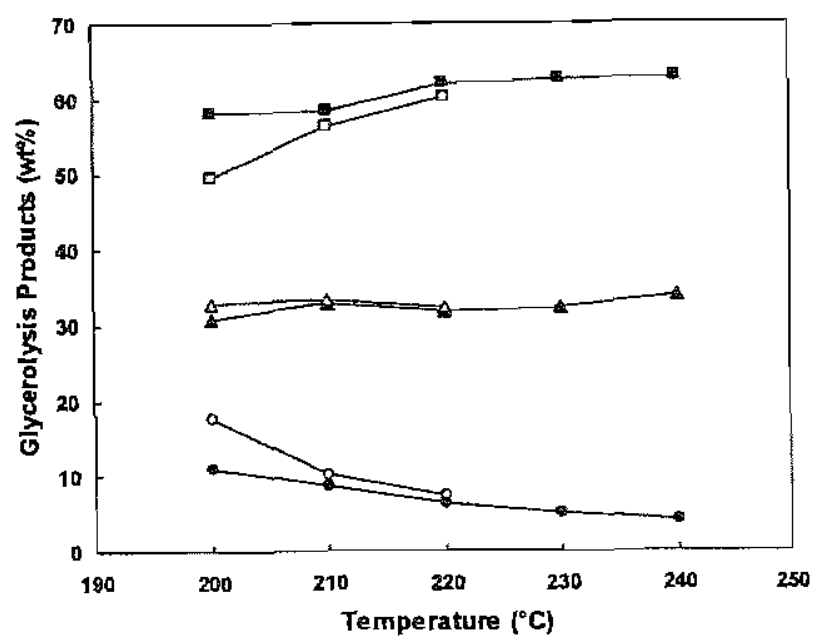

FIG. 1. The effect of reaction temperature and mixing rate on the continuous glycerolysis of soybean oil with pure giycerol, subject to a flow of $40 \mathrm{~mL} / \mathrm{mi}$ and a $2.5: 1 \mathrm{molar}$ ratio of glycerol/TG: (1), MG; (A), DG; and (-), TG. Open and solid symbols indicate rotor speeds of 360 and $3600 \mathrm{rpm}$, respectively. 


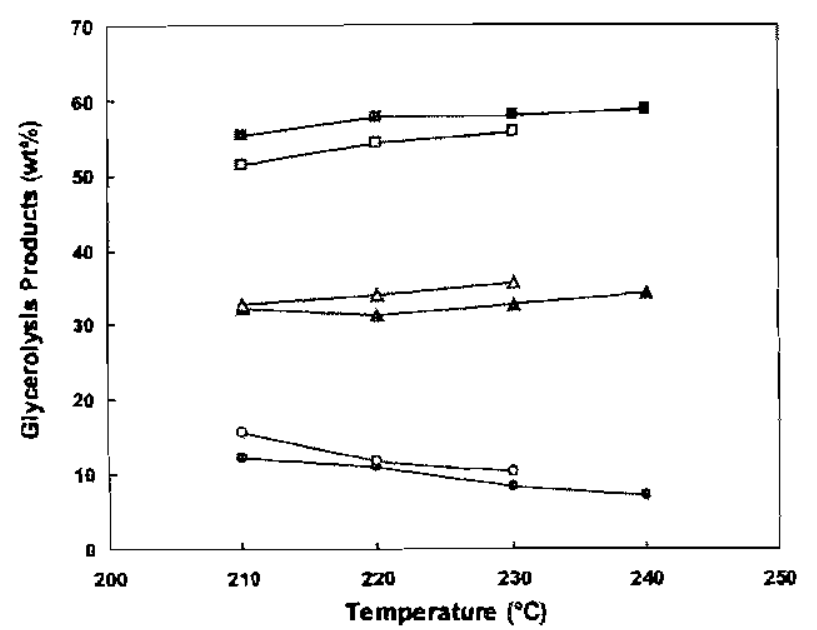

FIG. 2. Thie effect of reaction temperature and mixing rate on the continuous givcerolysis of soybearr oil with pure glycerol, subject to a filow of $50 \mathrm{~mL} / \mathrm{min}$ and a $2.5: 1$ ratio glyceroliTC: (G), MG; (\$), DG; and (-), TG. Open and solid symituols indicate rotor speeds of 360 and 3600 rpm, respectively.

librium tor the esterification reactions at different glycerol/TG molar ratios and, a thermodynamically limited situation.

Effect of temperature and mixing intensity. Temperature and mixing affect the degree of solubility of glycerol in the TG phase as well as the interaction of the two phases and therefore are critical to the extent of the glycerolysis reaction. At room temperature, the solubility of glycerol in TG is less than $5 \mathrm{wt} \%$, but it increases to about 45-55 wt\% (based on the origin of the natural TG) at temperatures as high as $250^{\circ} \mathrm{C}$. The higher solubility of glycerol in the TG phase leads to a shift in the equilibrium and consequently higher degrees of esterification. Another parameter investigated in this study was the effect of mixing intensity on the formation of glycerolysis products. Mixing affects the interfacial area, reduces diffusion-related rate limitations and consequently the rate of mass urausfer between the phases. Variations in mixing energy can affect the reaction kinetics. Changes in mixing and temperature could result in parallel effects on the formation of the products. Mixing energies of 10 and $100 \%$ of the maximum possible power to the mixer motors were tested. Given the extreme submission of the mixing energy in the experiments, our goal was to make distinctions between kinetic and thermodynamic effects.

Experiments were performed to investigate the effects of mixing and temperature on the glycerolysis products. Results presented in Figures 1 and 2 are for flow rates of 40 and 50 $\mathrm{mL} / \mathrm{min}$, respectively. Each figure contains two sets of runs at rotor speeds of 360 and $3600 \mathrm{rpm}$, which correspond to 10 aud $100 \%$ power into the mixer motor. As was expected, the formation of $\mathrm{MG}$ in the process increased when the reaction temperature was increased. However, at higher mixing intensities, this effect became minimal. Figures 1 and 2 also revealed that the formation of MG was higher at the lower flow rate of 40 $\mathrm{mL} / \mathrm{min}$. For example, at a flow rate of $40 \mathrm{~mL} / \mathrm{min}$ (Fig. 1) and rotor speed of $3600 \mathrm{rpm}$, when the temperature was increased from 200 to $220^{\circ} \mathrm{C}$ the concentration of $\mathrm{MG}$ in the reaction product increased from about 58 to $62 \mathrm{wt} \%$ and then leveled off as the reaction temperature was increased further to $240^{\circ} \mathrm{C}$. Similarly, at $50 \mathrm{~mL} / \mathrm{min}$ and otherwise identical conditions (Fig. 2), the concentration of $\mathrm{MG}$ in the reaction product increased from 55 to $58 \mathrm{wt} \%$ as temperature was raised from 210 to $220^{\circ} \mathrm{C}$ and then leveled off. The observarions clearly show that in both cases the state of equilibrium was approached. 'The results compares well with the work of Brandner and Birkmeier (17), who reported about $54 \mathrm{wt} \% \mathrm{MG}, 36 \mathrm{wt} \% \mathrm{DG}$, and 10 wt $\%$ TG for the glycerolysis of trioleate with about a $2.5: 1$ molar ratio of glycerol to trioleate reacted for $2.5 \mathrm{~h}$ at $200^{\circ} \mathrm{C}$.

The reaction results at lower mixing intensities presented in Figures 1 and 2 could help in making the distinction between the kinetic and thermodynamic effects. For example, at 40 $\mathrm{mL} / \mathrm{minin}$ flow, $360 \mathrm{rpm}$, and $200^{\circ} \mathrm{C}$ (Fig. 2), the formation of MG was about 49 wt $\%$ compared with about $58 \mathrm{wt} \%$ at 3600 rpm and otherwise identical conditions. This clearly shows the diffusion limitations caused by the lower mixing intensity, which affects the interfacial transport between the phases. At higher mixing intensities, this barrier was minimized and the formation of $\mathrm{MG}$ approached the equilibrium levels. At higher temperatures (e.g., $220^{\circ} \mathrm{C}$ in Fig. 1), the solubility of glycerol in the TG phase increased and the effect of mixing became less significant. Similar results, with a slightly lower concentration for $M G$ in the reaction product, were observed at $50 \mathrm{~mL} / \mathrm{min}$ (Fig. 2).

Ultimately, operation at lower temperatures is desirable because it eliminates the potential for the decomposition of reactant and consequential formation of undesirable products, which are knowu to affect the taste and color of the final product adversely.

Crude glycerol in continuous glycerolysis. Transesterification of TG with alcohols results in alkyl esters of FA, better known as biodiesel. With the growing demand for the production of biodiesel, large volumes of crude glycerol are potentially available for chemical conversions and other uses. Utilization of crude glycerol is desirable une to the rather difticult and expensive purification procedure involved. Crude glycerol from the transesterification process contains most of the excess methanol used in the process. Additionally, most of the catalyst used in the process, some FAME, and traces of MG, DG, and TG are also present in this product. However, atter its neutralization, and the removal of methanol and FAME, the other impurities in the glycerol are practically the same as those preseut in the soybean oil and they are not expected to interfere with the reactions involved when it is used in the glycerolysis of soybean oil.

Crude glycerol was tested in a series of experiments to determine its potential as a starting material in the contiuuous glycerolysis process. In a previous study (15), the feasibility of this material in batch glycerolysis process was tested and determined to be satisfactory. The percentage of $\mathrm{MG}$ in batch glycerolysis with crude glycerol was about $53 \mathrm{wt} \%$ at $245^{\circ} \mathrm{C}$, which was at about the same level for the batch glycerolysis of 


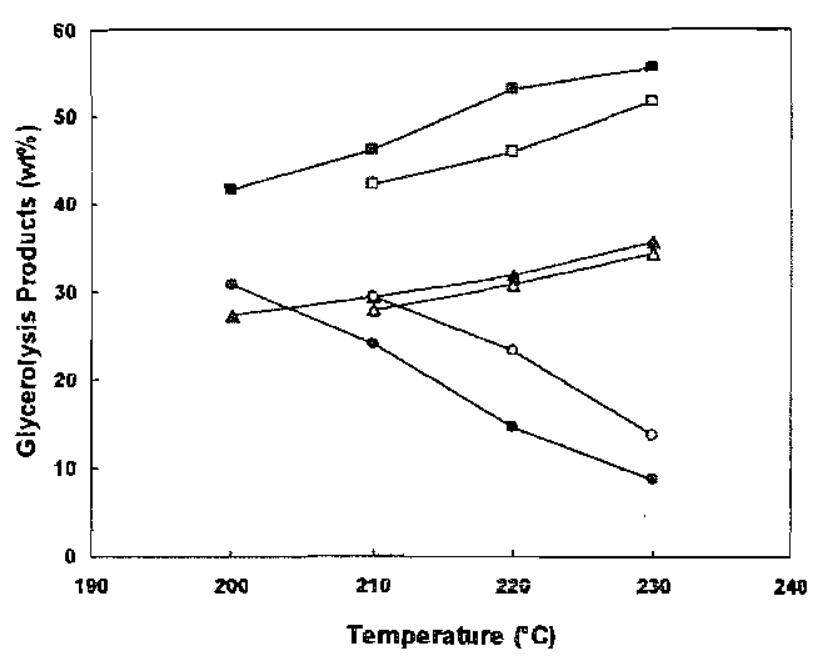

FIG. 3. The effect of reaction temperature and mixing rate on the cor:tinuous gycerolysis of soybean oil with crude glycerol, subject to a flow of $50 \mathrm{~mL} / \mathrm{min}$ and a 2.5:1 ratio glycerol/TG: (N), MG; (A), DG; and (-), TC. Open and solid symbols indicate rotor speeds of 360 and 3600 rom, respectively.

pure glycerol (15). The experimental results for crude glycerol in continuous glycerolysis process are presented in Figure 3. The total flow of material in these experiments was $50 \mathrm{~mL} / \mathrm{min}$, and the molar ratio of glycerol to TG was at 2.5. The trend of change for crude glycerol reactions in the glycerolysis process was very similar to and slightly lower than the experiments with pure glycerol (Fig. 2). The concentration of $\mathrm{MG}$ increased as the reaction temperature and the mixing intensity were increased. At a rotor speed of $360 \mathrm{rpm}$ and a temperature of $230^{\circ} \mathrm{C}$, the concentration of $\mathrm{MG}$ in the product was about 52 wt $\%$, which was slightly lower than the result for the continuous process with pure glyceroI ( $58 \mathrm{wt} \%$ ) and consistent with our previons result of $53 \mathrm{wt} \%$ in batch glycerolysis with crude glycerol (15). At a rotor speed of $3600 \mathrm{rpm}$ and temperature of $230^{\circ} \mathrm{C}$, the concentration of $\mathrm{MG}$ was about $56 \mathrm{wt} \%$ compared to about $62 \mathrm{wt} \%$ for the continuous reaction with pure glycerol (see Fig. 2). Results also confirmed our previous findings that the formation of $\mathrm{MG}$ was enchanced as a result of higher mixing iutensities due to an increased rate of mass transfer. The slightly lower rate for the crude glycerol could be attributed to the presence of impurities that which may have affected the extent of the solubility of glycerol in the TG phase and/or may have caused additional diffusion barriers for mass transport.

\section{ACKNOWLEDGMENTS}

The authors express their gratitude to USDA Cooperative State Research Service, Nebraska Soybean Board, and Stratco Inc. for their support of this work.

\section{REFERENCES}

1. Meffert. A., Technical Uses of Fatty Acid Esters, J. Amer. Oil Chem. Soc. 61:255-258 (1984).

2. Lauridsen, J.B., Food Emulsifiers: Surtace Activity, Edibility, Manufacture, Composition, and Application, Ibid. 53:400-407 (1976).

3. Sonntag, N.O.V., Glycerolysis of Fats and Methyl Esters: Status. Review, and Critique, Ibid. 59:795 A-802A (1982).

4. Cao, S.G., X.G. Gao, and K.E. Zhang, Enzymatic Preparation of Monoglycerides via Glycerolysis of Fats and Oils Catalyzed by Lipase from Pseudomonas Species, Ann. NY Acad. Sii. 799:670-677 (1996).

5. Noureddini, H., and S.E. Harmeier, Enzymatic Glycerolysis of Soybean Oil, J. Am. Oil Chem. Soc. 75:1359-1365 (1998).

6. Elfman-Borjesson, I., and M. Harrod, Synthesis of Monoglycerides by Glycerolysis of Rapeseed Oil Using Immobilized Lipase, Ibid. 76:701-708 (1999).

7. Rendon, A. A. Lopez-Munguia, and A. Castillo, Solvent Engineering Applied to Lipaze-Catalyzed Glycerolysis of Triolein, Ibid. 78:1061-1066 (2001).

8. Jackson, M.A., and I.W. King, Lipase-Catalyzed Glycerolysis of Soybean Oil in Supercritical Carbon Dioxide, Ibid. 74:103-106 (1997).

9. Krustanov, P.. I. Marinchevski, R. Chobanova, and N. Pekhlivanov, Technology for the Production of Monoglyceride Emulsifiers (abstract), Maslo-Sapunena Prom. 87:203382v (1974).

10. Birnbauı, H., and J. Lederer, Process for Producing Monoglycerides of Farty Acids, U.S. Patent 3,102,129 (1963).

11. Demmering. G., and G. Effey, Continuous Production of Fatty Acid Monoglycerides, German Patent 3,020,566 (1981).

12. Allen. R.R., and R.L. Campbell Jr., Process for the Manufacture of Fatty Acid Esters, U.S. Patent 3,313,834 (1967).

13. Chang. S.S. and L. Weidermann, Continuous Manufacture of Monoglycerides, U.S. Patent 3,079,412 (1963).

14. Official Methods and Recommended Practices of the American Oil Chemists' Society, 4th edn., edited by D. Firestone, AOCS Press, Cbampaign, 1993, Method Ca 5a-40.

15. Noureddini, H., D. Harkey, and V. Medikonduru, A Continuous Process for the Conversion of Vegetable Oils into Methyl Esters of Fatty Acids, J. Am. Oil Chem. Soc. 75:1755-1783 (1998).

16. Noureddini, H., and V. Medikonduru, Glycerolysis of Fats and Methyl Esters, Ibid. 74:419-425 (1997).

17. Brandner, I.D., and R.L. Birkmeier, Relative Esterification of the Primary and Secondary Hydroxyl Groups of Glycerol, Sbid. $37: 390-396$ (1960).

[Received July 28, 2003; accepted October 8, 2003] 